\title{
Peripapillary choroidal neovascularization in pars planitis
}

Sonia Mehta ${ }^{1,2}$, Luxme Hariharan², Allen $\mathrm{C} \mathrm{Ho}^{3}$ and John H Kempen ${ }^{2,4,5^{*}}$

\begin{abstract}
Background: Choroidal neovascularization (CNV) is a rare complication of intermediate uveitis. Risk factors are not well-characterized. Here, we describe a case of peripapillary CNV in a patient with intermediate uveitis and explore the pathophysiology and treatment of this condition. This study is a case report and review of the literature.

Results: A 15-year-old boy with intermediate uveitis - suppressed for the preceding year on immunosuppressive therapy and low-dose corticosteroids - and chronic disc swelling presented with unilateral metamorphopsia, peripapillary subretinal hemorrhage, and subretinal fluid. Fluorescein angiogram confirmed the presence of an active choroidal neovascular membrane. Treatment with intravitreal bevacizumab 1.25 mg every 4 weeks for 4 months resulted in resolution of subretinal fluid, subretinal hemorrhage, and regression of the CNV. The patient's intermediate uveitis remained inactive throughout this time.
\end{abstract}

Conclusion: Review of the existing literature and pathophysiologic consideration suggests that chronic disc edema may be a risk factor for this condition. Peripapillary CNV in the context of intermediate uveitis appears to respond well to VEGF-inhibitor therapy.

Keywords: Choroidal neovascularization, CNV, Intermediate uveitis, Pars planitis, Peripapillary

\section{Findings \\ Background}

Choroidal neovascularization (CNV) occurs rarely in the context of intermediate uveitis [1]. Only three such cases have previously been reported in the English literature, two of which presented in a peripapillary location $[1,2]$. In the Systemic Immunosuppressive Therapy for Eye Diseases (SITE) Cohort Study, representing the experience of five US tertiary uveitis centers including ours, 0 / 1,978 patients with intermediate uveitis presented with peripapillary CNV (upper limit of a one-sided 97.5\% confidence interval $=0.19 \%$ ). Here, we report a case of peripapillary $\mathrm{CNV}$ in a patient with intermediate uveitis and explore the pathophysiology and outcome of this condition. The project was conducted in accordance with the principles of the Declaration of Helsinki, with

\footnotetext{
* Correspondence: john.kempen@uphs.upenn.edu

${ }^{2}$ Ocular Inflammation Service, Department of Ophthalmology, Scheie Eye Institute, University of Pennsylvania, Philadelphia, PA 19104, USA

${ }^{4}$ Department of Biostatistics \& Epidemiology, Perelman School of Medicine, University of Pennsylvania, Philadelphia, PA 19104, USA

Full list of author information is available at the end of the article
}

the approval of the governing Institutional Review Board of the University of Pennsylvania.

\section{Case report}

After completion of the SITE Cohort Study at our center, a 15-year-old male presented to our institution with blurry vision in the inferotemporal quadrant of the left eye for 1 day, which upon further questioning represented metamorphopsia. The patient denied redness, eye pain, light sensitivity, or floaters. The patient had longstanding intermediate uveitis and chronic disc swelling, which we observed to be suppressed for the past year. At the time of presentation with metamorphopsia, the patient was taking mycophenolate mofetil $1 \mathrm{~g}$ twice daily, methotrexate 25 $\mathrm{mg}$ once weekly, and folic acid $1 \mathrm{mg}$ daily. He was otherwise healthy, and past medical history was unremarkable. Previous laboratory workup for conditions associated with intermediate uveitis was negative.

The patient's best corrected visual acuity was 20/20 in both eyes. Pupils, intraocular pressures, and color vision were normal. No afferent pupillary defect was present. Visual field was full in the right eye and showed an inferotemporal defect in the left eye. Slit lamp biomicroscopy 
was normal in both eyes showing no anterior or vitreous cells or flare. Fundus examination of the right eye showed stable chronic disc swelling but was otherwise unremarkable. In addition to disc swelling, the left eye fundus showed peripapillary subretinal hemorrhage and subretinal fluid extending into the macula (Figure 1a,b). Fluorescein angiogram showed an active choroidal neovascular membrane adjacent to the disc in the left eye (Figure 1c, d). There was no evidence of cystoid macular edema, periphlebitis, snowballs, or snowbanking in either eye on clinical exam, optical coherence tomography (OCT), and fluorescein angiogram. B-scan ultrasound showed bilateral disc elevation with fluid and positive $30^{\circ}$ sign. Echography showed no evidence of optic disc drusen. MRI of the brain and orbits was normal; lumbar puncture revealed an opening pressure of $180 \mathrm{~mm} \mathrm{H}_{2} \mathrm{O}$ at the upper limit of normal range.

The patient was treated with intravitreal bevacizumab $1.25 \mathrm{mg}$ every 4 weeks for 4 months and retrobulbar triamcinolone acetonide $40 \mathrm{mg}$ once at 6 weeks after presentation with the $\mathrm{CNV}$. Acetazolamide $500 \mathrm{mg}$ twice daily for several weeks after presentation did not decrease the disc swelling, at which point acetazolamide was discontinued. At 8 months follow-up, the patient's vision was stable and exam showed resolution of subretinal hemorrhage and fluid (Figure 2a,b) but continued traction lines in the area of the affected retina. Because the disc swelling gradually resolved over several months of follow-up, no further lumbar punctures were obtained.

Throughout this time, the patient's intermediate uveitis remained inactive. He was maintained on mycophenolate mofetil $1 \mathrm{~g}$ twice daily and methotrexate $25 \mathrm{mg}$ once weekly. He was followed-up at our institution regularly over the next 3 years and did well. At last followup, the uveitis was inactive; no recurrence of $\mathrm{CNV}$ or disc swelling was noted throughout this period. His complaints of metamorphopsia gradually subsided, but he is still aware of metamorphopsia when he covers the right eye corresponding to the still-persistent traction lines in the nasal macula. It remains unclear whether the etiology of the disc swelling was from slowly resolving inflammatory disc edema, corticosteroid-induced intracranial hypertension, or both.

\section{Discussion}

Most cases of CNV in uveitis occur in posterior uveitis or panuveitis. CNV in intermediate uveitis is rare with only three cases reported in the literature; two of the three cases were noted to occur adjacent to the disc (Table 1) [1,2]. Arkfeld and Brockhurst reported the first of these cases in a 29-year-old female with sarcoidrelated bilateral intermediate uveitis [2]. The patient had disc swelling and active intermediate uveitis in the involved eye which was treated with oral prednisone.
The disc swelling occurred in the involved eye 10 months prior to the onset of peripapillary CNV. She was treated with argon green laser photocoagulation and did well with CNV regression and significant visual improvement. Garcia et al. reported the second case of a 15-year-old female who presented with intermediate uveitis, vasculitis, papillitis, and peripapillary CNV [1]. The patient was treated with systemic corticosteroids and one dose of intravitreal bevacizumab $1.25 \mathrm{mg}$. On follow-up 7 months later, vision improved significantly, vasculitis resolved, and CNV regressed. Garcia et al. reported another case of a 27-year-old female with bilateral intermediate uveitis and chronic cystoid macular edema in the right eye [1]. Systemic workup for conditions associated with intermediate uveitis including sarcoidosis evaluation was negative. The patient was noncompliant with the treatment and presented 1 year after a flare-up with decreased vision and a subfoveal pigmented granuloma in the right eye which the authors described as regressed $\mathrm{CNV}$.

Histopathologic studies have provided insight into the potential mechanisms in the development of peripapillary $\mathrm{CNV}$ [3]. Sarks provided clinicopathologic correlation of 21 eyes with peripapillary CNV from AMD [3]. Based on histopathologic evidence, Sarks hypothesized that peripapillary CNV originates either from the choroidal vessels passing around the termination of Bruch's membrane or from the choroidal vessels passing through defects in Bruch's membrane. In the above reported cases of peripapillary CNV in intermediate uveitis, it is interesting to note that chronic disc edema was present prior to the onset of all cases. Arkfeld and Brockhurst hypothesized that chronic disc swelling may increase the potential space between Bruch's membrane and swollen disc tissue facilitating ingrowth of choroidal vessels around the termination of Bruch's membrane [2]. Alternatively, chronic disc swelling may result in the deformation of the peripapillary Bruch's membrane leading to breaks in Bruch's membrane facilitating ingrowth of the choroidal neovascular tissue under the RPE [4]. Peripapillary CNV has also been observed in conditions causing chronic disc swelling such as idiopathic intracranial hypertension and hydrocephalus [5-8].

Peripapillary $\mathrm{CNV}$ is characterized clinically by the presence of a choroidal neovascular membrane adjacent to the disc producing subretinal hemorrhage, fluid, and/ or exudate [4]. OCT characteristics suggestive of $\mathrm{CNV}$ include the presence of subretinal fluid, subretinal hemorrhage, subretinal hyperreflective lesion, and intraretinal fluid. On fluorescein angiogram, well-defined $\mathrm{CNV}$ appears as a lacy network of capillary plexuses with leakage as the angiogram progresses [9]. Occult $\mathrm{CNV}$ can appear as an area of stippled hyperfluorescence on angiogram. The choroidal neovascular 

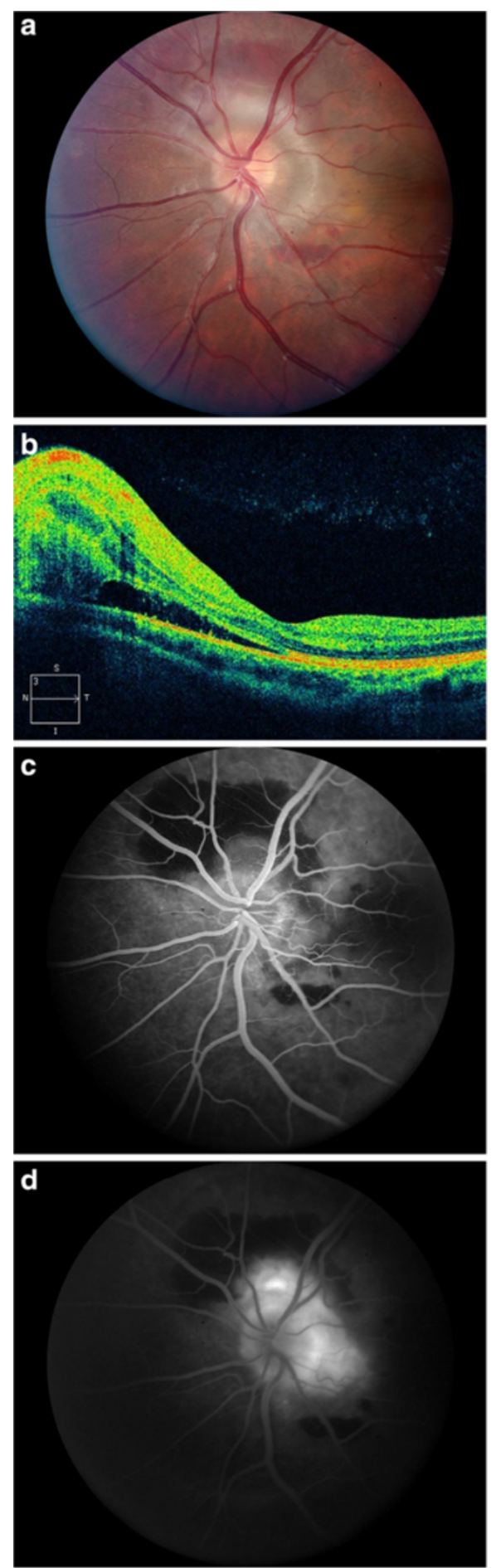

Figure 1 Color fundus photograph, optical coherence tomography, and fluorescein angiogram at presentation. (a) Color fundus photograph of the left eye at presentation demonstrating disc swelling with peripapillary subretinal hemorrhage and subretinal fluid. (b) Intraretinal and subretinal fluid temporal to the disc is evident on optical coherence tomography. (c) Early and (d) late fluorescein angiograms of the left eye reveals a choroidal neovascular membrane adjacent to the disc. 
Table 1 Literature summary of choroidal neovascularization in intermediate uveitis

\begin{tabular}{|c|c|c|c|c|c|c|c|c|}
\hline & Case & $\begin{array}{l}\text { Age (year)/ } \\
\text { gender }\end{array}$ & $\begin{array}{l}\text { Systemic } \\
\text { workup }\end{array}$ & Location of CNV & $\begin{array}{l}\text { Active intraocular } \\
\text { inflammation at the } \\
\text { time of CNV }\end{array}$ & Treatment & Outcome & Notes \\
\hline $\begin{array}{l}\text { Arkfeld and } \\
\text { Brockhurst } \\
{[2]}\end{array}$ & 1 & 29/female & Sarcoidosis & $\begin{array}{l}\text { Peripapillary } \\
\text { (temporal to disc) }\end{array}$ & No & $\begin{array}{l}\text { Argon green laser } \\
\text { photocoagulation }\end{array}$ & $\begin{array}{l}\text { Regressed } \\
\text { CNV }\end{array}$ & $\begin{array}{l}\text { Chronic disc swelling } \\
\text { present prior to CNV }\end{array}$ \\
\hline $\begin{array}{l}\text { Garcia et al. } \\
{[1]}\end{array}$ & 2 & 15/female & NR & $\begin{array}{l}\text { Peripapillary- } \\
\text { (temporal to disc) }\end{array}$ & Yes & $\begin{array}{l}\text { Intravitreal } \\
\text { bevacizumab } \times 1\end{array}$ & $\begin{array}{l}\text { Regressed } \\
\text { CNV }\end{array}$ & Disc swelling present \\
\hline $\begin{array}{l}\text { Garcia et al. } \\
\text { [1] }\end{array}$ & 3 & 27/female & Idiopathic & Subfoveal & NR & None & $\begin{array}{l}\text { Regressed } \\
\text { CNV }\end{array}$ & $\begin{array}{l}\text { Chronic cystoid macular } \\
\text { edema present prior to } \\
\text { CNV }\end{array}$ \\
\hline $\begin{array}{l}\text { Present } \\
\text { report }\end{array}$ & 4 & 15/male & Idiopathic & $\begin{array}{l}\text { Peripapillary (superior } \\
\text { and temporal to disc) }\end{array}$ & No & $\begin{array}{l}\text { Intravitreal } \\
\text { bevacizumab } \times 4\end{array}$ & $\begin{array}{l}\text { Regressed } \\
\text { CNV }\end{array}$ & $\begin{array}{l}\text { Chronic disc swelling } \\
\text { present prior to CNV }\end{array}$ \\
\hline
\end{tabular}

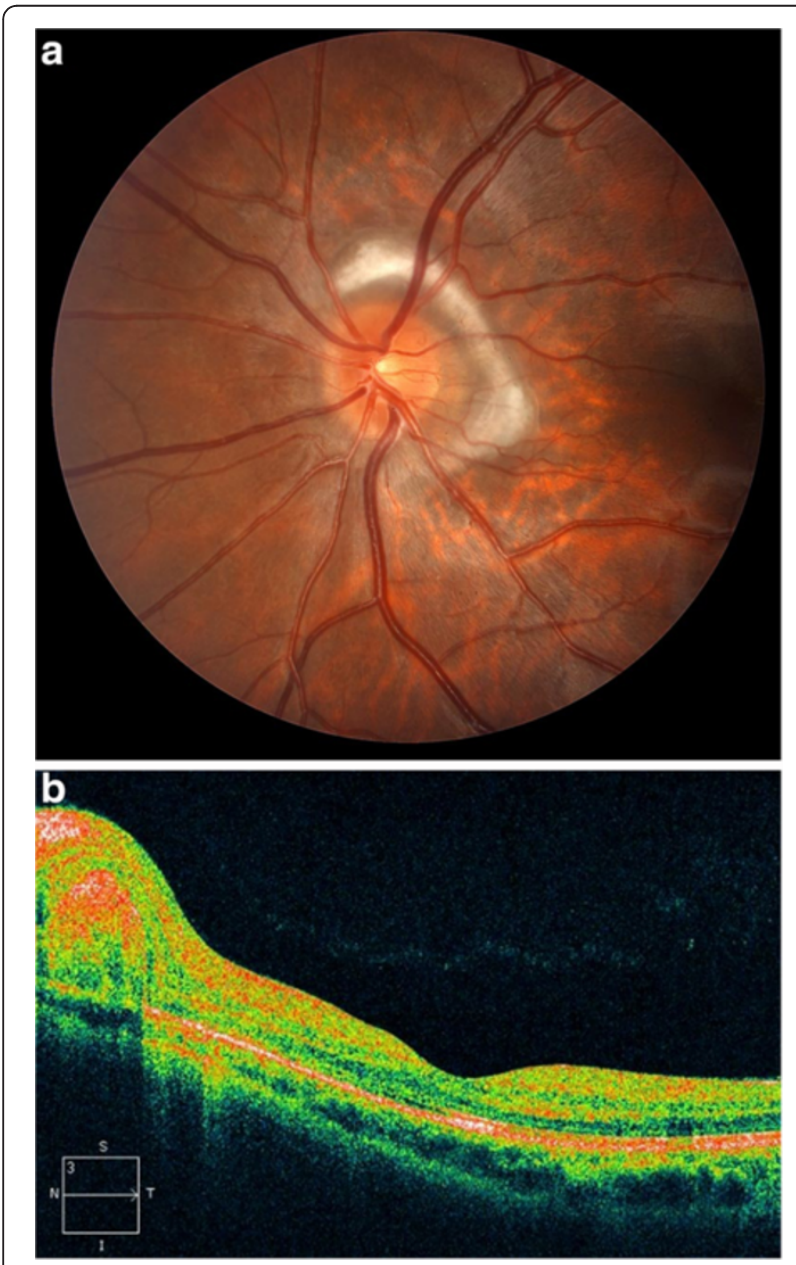

Figure 2 Color fundus photograph and optical coherence tomography at follow-up. (a) Color fundus photograph of the left eye 8 months after presentation showing resolution of the subretinal fluid and hemorrhage. (b) The subretinal fluid has resolved on optical coherence tomography. membrane may be obscured by hemorrhage, pigment hyperplasia, fibrous tissue, or serous pigment epithelial detachment [9].

Peripapillary CNV has certain unique features compared to its macular counterpart. First, peripapillary $\mathrm{CNV}$ is associated not just with diseases affecting chorioretinal tissue adjacent to the disc but also with diseases affecting the optic nerve head. For example, peripapillary $\mathrm{CNV}$ can be seen in optic disc drusen, congenital disc anomalies, tilted disc, and disc swelling [4]. Second, peripapillary CNV may develop from the breakthrough of abnormal choroidal blood vessels through Bruch's membrane in addition to growth of vessels around the termination of Bruch's membrane [2-4]. Third, the occurrence of clinical symptoms prior to the extension of the lesion into the fovea may allow detection and treatment of these lesions with potentially more favorable visual outcomes compared to their foveal counterparts [4].

Several treatment options exist for peripapillary CNV in uveitis including vascular endothelial growth factor inhibitors, argon laser photocoagulation, and photodynamic therapy [10-13]. In the above cases, all patients underwent treatment with either argon laser photocoagulation or intravitreal bevacizumab (as used in our case) and did well with significant improvements in vision and CNV regression. For lesions adjacent to vital structures such as the optic disc, therapy with bevacizumab injection likely is safer than laser photocoagulation or photodynamic therapy and is reasonably cost-effective.

In conclusion, patients with intermediate uveitis and chronic disc swelling may be at risk for peripapillary CNV. Control of inflammation without the use of corticosteroids likely will improve disc swelling in most cases, even though resolution of disc swelling may be delayed in some instances, as in our case. Corticosteroidinduced or idiopathic intracranial hypertension should 
be suspected in cases with ongoing disc swelling without active inflammation. Chronic disc swelling should be resolved if possible to avoid complications. CNV has been reported to develop during times of quiescence or active inflammation [1,2]. Management with a vascular endothelial growth factor inhibitor likely is the treatment of choice, along with control of inflammation and control of any associated factors that may be present such as intracranial hypertension [13]. Based on the limited number of observations available, the prognosis of this condition with appropriate treatment appears favorable.

\section{Competing interests}

JHK is a consultant at Lux Biosciences, Allergan, Alcon, Sanofi-Pasteur, and Xoma. All other authors have no competing interests.

\section{Authors' contributions}

SM and JHK designed and conducted the study. SM, LH, ACH, and JHK collected, managed, analyzed, and interpreted the data and prepared, reviewed, and approved the manuscript. All authors read and approved the final manuscript.

\section{Acknowledgments}

This study was supported primarily by a generous contribution to the Scheie Eye Institute by the Klein family. The SITE Cohort Study was supported by the National Eye Institute Grant EY014943 (JHK). Additional support was provided by the Research to Prevent Blindness and the Paul and Evanina Mackall Foundation.

\section{Author details}

'Department of Ophthalmology, Emory University School of Medicine, Atlanta, GA 30307, USA. ${ }^{2}$ Ocular Inflammation Service, Department of Ophthalmology, Scheie Eye Institute, University of Pennsylvania, Philadelphia, PA 19104, USA. ${ }^{3}$ Retina Service, Wills Eye Institute, Philadelphia, PA 19107, USA. ${ }^{4}$ Department of Biostatistics \& Epidemiology, Perelman School of Medicine, University of Pennsylvania, Philadelphia, PA 19104, USA. ${ }^{5}$ Center for Preventative Ophthalmology and Biostatistics, Perelman School of Medicine, University of Pennsylvania, 3535 Market St., Suite 700, Philadelphia, PA 19104, USA.

Received: 11 September 2012 Accepted: 12 September 2012 Published: 15 January 2013

\section{References}

1. Garcia CA, Segundo Pde S, Gardcia Filho CA, Garcia AC (2008) Intermediate uveitis complicated by choroidal granuloma following subretinal neovascular membrane: case reports. Arq Bras Oftalmol 71(6):890-893

2. Arkfeld DF, Brockhurst RJ (1985) Peripapillary subretinal neovascularization in peripheral uveitis. Retina 5:157-160

3. Sarks S (1973) New vessel formation between the retinal pigment epithelium in senile eyes. Br J Ophthlamol 57:951-965

4. Lopez PF, Green WR (1992) Peripapillary subretinal neovascularization. A review Retina 12(2):147-171

5. Jamison RR (1981) Subretinal neovascularization and papilledema associated with pseudotumor cerebri. Am J Ophthalmol 91:312-317

6. Troost BT, Sufit RL, Grand MG (1979) Sudden monocular visual loss in pseudotumor cerebri. Arch Neurol 36:440-442

7. Morse PH, Leveille AS, Antel JP, Burch JV (1981) Bilateral juxtapapillary subretinal neovascularization associated with pseudotumor cerebri. Am J Ophthalmol 91:312-317

8. Nguyen C, Borruat FX (2005) Bilateral peripapillary subretinal neovessel membrane associated with chronic papilledema: report of two cases. Klin Monbl Augenheilkd 222(3):275-278

9. Gass JDM (1997) Diseases causing choroidal exudative and hemorrhagic localized (disciform) detachment of the retina and retinal pigment epithelium. In: Gass JDM (ed) Stereoscopic atlas of macular diseases. MosbyYear Book, Inc., St. Louis, pp 49-285
10. Mansour AM, Arevalo F, Ziemssen F, Mehio-Sibai A, Mackensen F, Adan A, Chan W, Ness T, Banker AS, Dodwell D, Tran THC, Fardeau C, Lehoang P, Mahendradas P, Berrocal M, Tabbarah Z, Hrisomalos N, Hrisomalos F, AlSalem K, Guthoff R (2009) Long term visual outcomes of intravitreal bevacizumab in inflammatory ocular neovascularization. Am J Ophthalmol 148:310-316

11. Arevalo JF, Adan A, Berrocal MH, Espinoza JV, Maia M, Wu L, Roca JA, Quiroz-Mercado H, Ruiz-Moreno JM, Serrano MA (2011) Intravitreal bevacizumab for inflammatory choroidal neovascularization: results from the Pan-American Collaborative Retina Study Group at 24 months. Retina 31:353-363

12. Lim Jl, Flaxel CJ, LaBree L (2006) Photodynamic therapy for choroidal neovascularization secondary to inflammatory chorioretinal disease. Ann Acad Med Singapore 35:198-202

13. O'Toole L, Tufail A, Pavesio C (2005) Management of choroidal neovascularization in uveitis. Int Ophthalmol Clin 45:157-177

doi:10.1186/1869-5760-3-13

Cite this article as: Mehta et al:: Peripapillary choroidal neovascularization in pars planitis. Journal of Opthalmic Inflammation and Infection 2013 3:13

\section{Submit your manuscript to a SpringerOpen ${ }^{\odot}$ journal and benefit from:}

- Convenient online submission

- Rigorous peer review

- Immediate publication on acceptance

- Open access: articles freely available online

- High visibility within the field

- Retaining the copyright to your article

Submit your next manuscript at $>$ springeropen.com 